\title{
Play behaviour by captive tree monitors, Varanus macraei and Varanus prasinus
}

\author{
DANIEL KANE ${ }^{1}$, ADAM C. DAVIS ${ }^{2} \&$ CHRISTOPHER J. MICHAELS ${ }^{1 *}$ \\ ${ }^{1}$ Zoological Society of London, London, NW1 4RY, UK \\ ${ }^{2}$ Bristol Zoological Society, Bristol Zoo Gardens, Bristol, BS8 3HA, UK \\ "Corresponding author e-mail: christopher.michaels@zsl.org
}

$P$ ay describes suites of behaviour that are perceived as 'non-serious'. Play has proven to be difficult to define although there have been many attempts to do so (see Burghardt, 2014). Initially, play was thought to be limited to mammals and birds, but efforts to define it more objectively have led to the identification of play in a variety of other taxa as diverse as octopodes (Kuba et al., 2006), fish (Burghardt et al., 2015), and reptiles including monitor lizards (e.g. Hill, 1946), turtles (Burghardt et al., 1996; Kramer \& Burghardt, 1998) and crocodilians (Lazell \& Spitzer, 1977; Dinets, 2015). The widely accepted definition of play is 'repeated, seemingly non-functional behaviour differing from more adaptive versions structurally, contextually, or developmentally, and initiated when the animal is in a relaxed, unstimulating, or low stress setting' (Burghardt, 2014). Here we report the play behaviour of two species of monitor in captivity, Varanus macraei at ZSL London Zoo (Zoological Society of London) and Varanus prasinus at Bristol Zoo (Bristol Zoological Society).

At ZSL London Zoo, observations were made on a pair of adult captive-bred blue tree monitors (V. macraei) aged 6 (female) and 7.5 (male) years. The animals were housed in a $3 \times 2 \times 1.5$ m enclosure with a heterogenous structure including branches and artificial rockwork, a waterfall and a naturalistic substrate comprising layers of humus and leaf litter. Heating (mercury vapour lamps; Arcadia/Osram) and lighting (T5 UVB emitting fluorescent lamps; Arcadia Reptile) arrays provided an ambient temperature gradient from $25-28{ }^{\circ} \mathrm{C}$ (day), 23$26{ }^{\circ} \mathrm{C}$ (night) and a diurnal basking zone with temperatures between $39-43{ }^{\circ} \mathrm{C}$ and a maximum UVi of 5 , in accordance with best husbandry practices for the species (Ziegler et al., 2009). The animals were fed a variety of invertebrate and vertebrate prey; these were generally broadcast in the enclosure to allow the animals to engage in natural hunting and feeding behaviour. The animals were also target-trained using operant conditioning with food items as a reward. The enclosure had been repeatedly planted with a variety of live plants, especially Scindapsus and Philodendron, in order to increase structural and environmental complexity, as well as for aesthetic appeal to the public.

At Bristol Zoo, juvenile (0.5-1.5 years), captive-bred $V$. prasinus were reared in custom glass-fronted fibreglass enclosures measuring $60 \times 60 \times 70 \mathrm{~cm}$. Enclosures are furnished with live plants (e.g. Ficus sp., Schefflera arboricola, Scindapsus sp.), branches, cork bark tubes and damp refugia. The substrate consisted of humus and leaf litter and water was provided with a small $10 \mathrm{~cm}$ water bowl. Lighting (T5 UVB emitting fluorescent lamps, Arcadia Reptile; T5 6500K lamps, Philips) and heating ( $75 \mathrm{~W}$ halogen bulbs, Sylvania/Osram) provided ambient temperatures of $27-31^{\circ} \mathrm{C}$ (day) and $24-26$ ${ }^{\circ} \mathrm{C}$ (night), a basking site of $38-40{ }^{\circ} \mathrm{C}$ with a maximum UVi of 6.0 , and a photoperiod of $12: 12$. They were fed four times a week on a variety of insect prey that were usually broadcast in the enclosure.

\section{Observations on Varanus macraei}

Both specimens of $V$. macraei were repeatedly observed engaging in focussed destructive behaviour involving the leaves of plants for weeks or months after the plants were added. The behaviour included initial investigation and then removal of all or parts of individual leaves using mouth and front limbs to tear. The leaf sections removed were often transported some distance to a perch or hide where, using mouth and forelimbs, they were systematically shredded and then wiped in an exaggerated manner across rock work (Fig. 1 a). The fragments were typically not consumed (occasional, apparently incidental, ingestion of small fragments was observed), and once the leaf section is shredded, the lizards typically returned to the plant to obtain another piece. The behaviour was displayed at different times of day and was not associated with the presence of food.

\section{Observations on Varanus prasinus}

Several juvenile $V$. prasinus were observed removing leaves of Schefflera arboricola and Ficus benjamina and engaging in destructive behaviour (Fig. 2 a-c). It is not known whether these animals continued the behaviour past 1.5 years since by that age they were transferred from the collection. The behaviour was not observed in adult $V$. prasinus $(n=6)$ or $V$. macraei $(\mathrm{n}=3)$ maintained under similar conditions at Bristol Zoo. Individuals investigated a leaf with tongue flicking before removing it with their mouth, often shaking the head side to side while pulling, and using forelimbs to assist if necessary. On one occasion a freshly-fallen leaf was picked up from the floor of the enclosure. The leaves were then transported to a favoured perching area where the mouth and forelimbs were used to bite and tear them apart, usually into two or three pieces. The front limbs were used to hold leaves in position to allow the animal to release the leaf from its jaws and reposition its bite location and to hold the leaf in place while biting/mouthing and pulling to assist in tearing. This posture 
also allows the lizard to engage in forelimb raking, similar to prey handling behaviours described in several species of the Hapterosaurus subgenus by Greene (1986), Irwin (1996) and Hartdegen (2000). Exaggerated wiping of the leaves from side to side against the perch was also witnessed. Occasionally the leaf would be accidently dropped to the floor of the enclosure and the individual would retrieve it, usually chasing after it as quickly as it could, and then returning to its original position to continue the aforementioned behaviours. One individual was observed collecting a second leaf with mouth and forelimbs while keeping hold of another, where the destructive behaviour described was exhibited on two
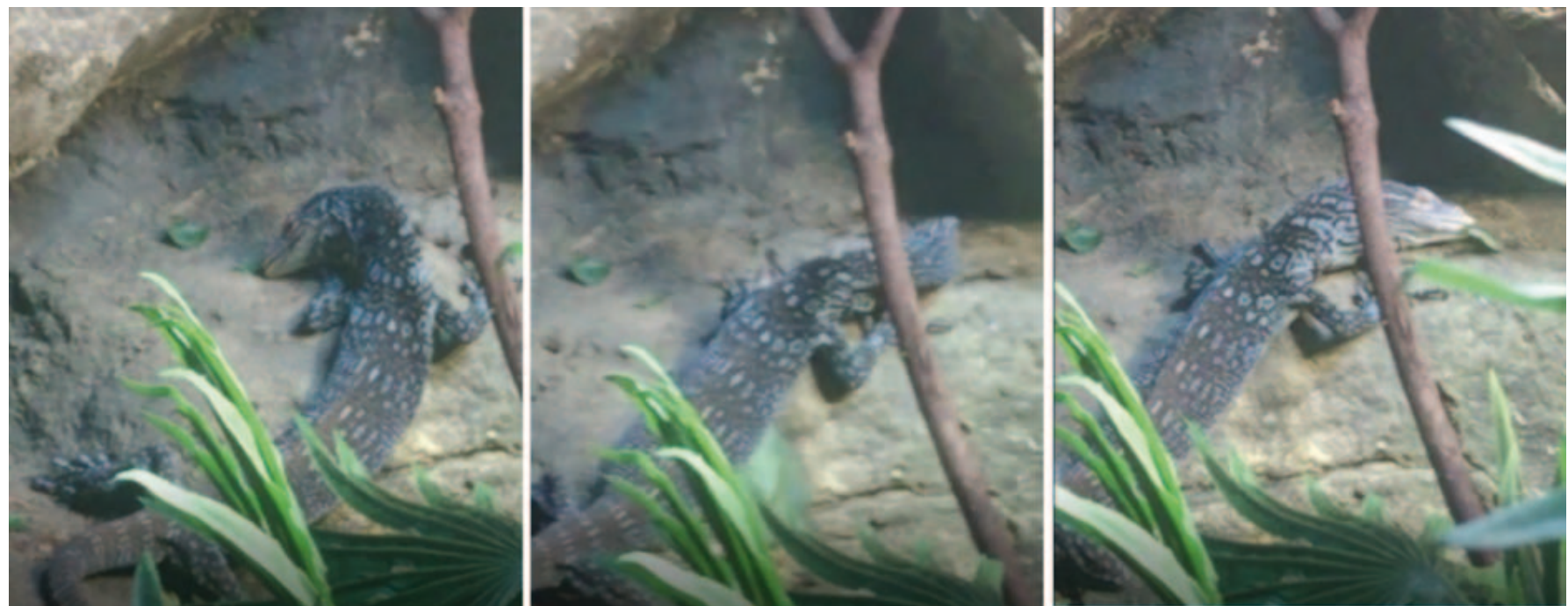

Figure 1. Stills image from mobile phone footage of a male V. macraei, surrounded by discarded leaf fragments collected from a Scindapsus plant c. $60 \mathrm{~cm}$ away from its retreat, systematically shredding a leaf fragment by wiping it across a rock face
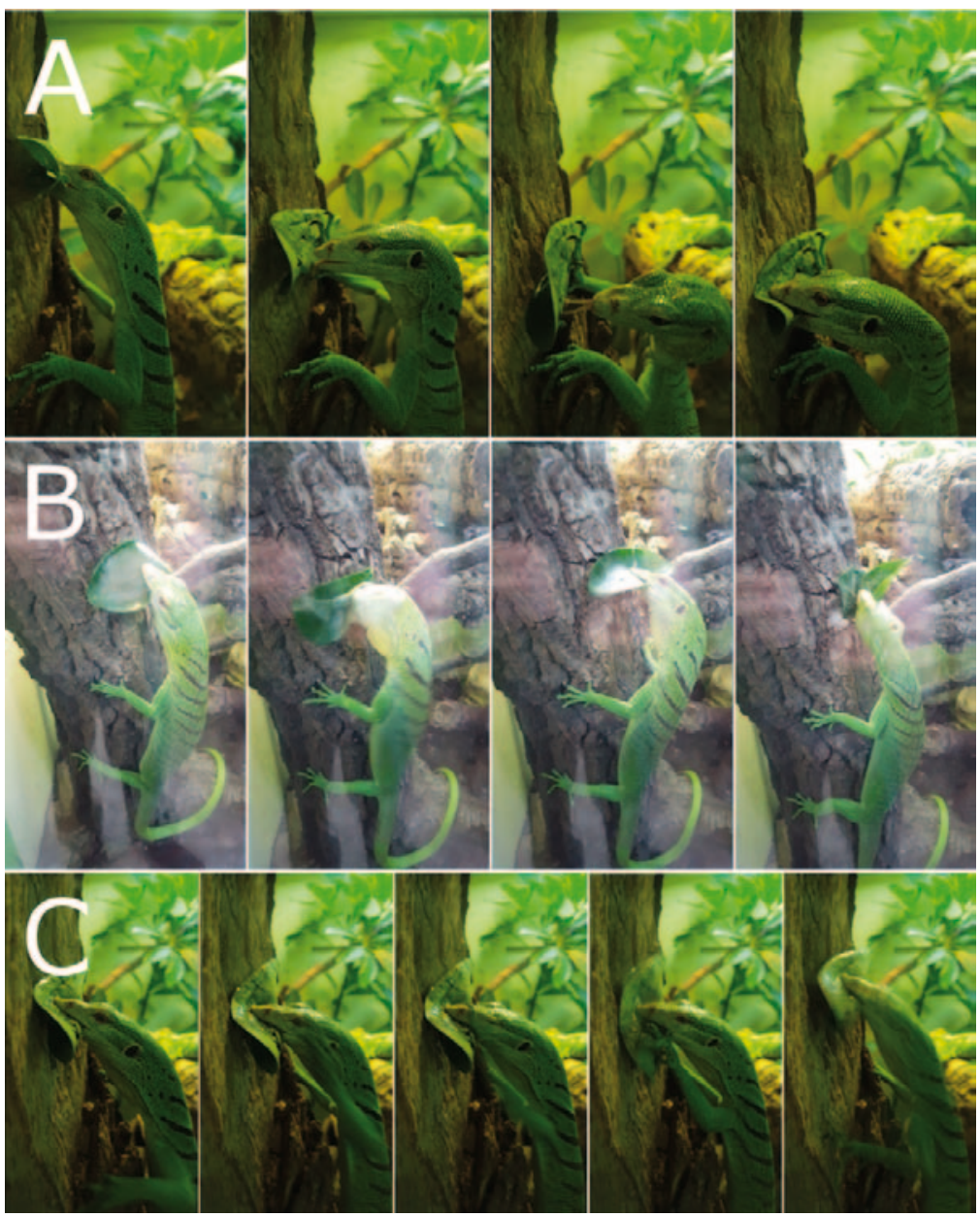

Figure 2. Stills images from mobile phone footage of a female $V$. prasinus using forelimbs in actions resulting in tearing a Schefflera leaf into several smaller fragments, A. repositioning bite location on leaf; $\mathbf{B}$. wiping leaf across branching; $\mathbf{C}$. forelimb raking leaf 
leaves at the same time. No attempts to consume any leaf fragments were observed. The behaviour was not associated with the presence of food and has been observed at different times of day, both on feed and non-feed days alike.

\section{Behavioural analysis}

We consider the observed behaviour to be the same across both monitor species and tested it against Burghardt's (2014) five criteria of play (in bold) as follows:

1) Incompletely functional in the context in which it appears: The lizards in this study derived no food by engaging in the behaviour, as in the vast majority of cases no plant matter was ingested; when this does occur, it is in extremely small quantities relative to the quantity of leaf that is shredded.

2) Spontaneous, pleasurable, rewarding, or voluntary: The behaviour was voluntary and, given that it is engaged in frequently, this suggests that there is a degree of 'reward' or positive reinforcement for the lizards, i.e. they may 'enjoy' it.

3) Different from other more serious behaviours in form (for example, is exaggerated) or timing (for example, occur early in life, before the more serious version is needed): The behaviour differs in form from 'serious' behaviours in that it is a) directed against foliage, which is not a part of the lizards' diet, b) the fragments are not consumed, and c) the tearing and wiping behaviour is exaggerated compared with the treatment of prey items.

4) Repeated, but not in abnormal and unvarying stereotypic form (for example, rocking or pacing): The behaviour was repeated, but is not stereotyped in that it occurs with different plants, in different parts of the enclosure, with different bout lengths and at different times of day.

5) Initiated in the absence of severe stress: The behaviour was exhibited without consistent stimulus and under normal conditions, under which the lizards display no abnormal behaviours or lack of behaviours that might be associated with stress.

Given that this leaf shredding behaviour fulfils Burghardt's (2014) five criteria for play, we label it as a candidate objectbased play behaviour (Held \& Špinka, 2011). The selection of leaves as the object of play is likely incidental and may reflect the fact that of all the materials in the enclosure, live plant leaves are the most suitable for easy tearing. Artificial silk plant leaves, also present in the enclosure, are extremely difficult to tear, while dried leaf litter crumbles rather than tears. Varanus komodoensis has also been reported to exhibit object play behaviour not dissimilar from the behaviour we describe in $V$. macraei and $V$. prasinus, whereby objects were picked up and subjected to shaking, mouthing and destructive behaviour resembling exaggerated predatory behaviour but not leading to ingestion (Hill, 1946; Burghardt et al., 2002; Burghardt, 2005).

Burghardt (2010) described three play processes. Primary-process play is the simplest level and grows out of excess energy and low behavioural thresholds giving rise to behaviour with no long-term consequences, good or bad. Secondary-process play begins to develop immediate physiological benefits for the animal, such as maintaining muscular function, or cognitive capacity. Tertiary-process play is necessary for the completion of developmental milestones. The transition from primary through to tertiary play processes underpins Surplus Resource Theory (SRT; Burghardt 1984; 2005; 2010; 2014). SRT provides a unifying approach to the different historic attempts to explain play behaviour and allows for the initiation of a play behaviour as a non-adaptive result of excess energy to become a fundamentally necessary part of an animal's development.

The behaviour reported here in V. prasinus and V. macraei, as well as similar behaviours reported in $V$. komodoensis (Burghardt et al., 2002), may fall into the primary-process category. Not all individual monitor lizards of the species described here engage in this sort of behaviour (even within the same collections as the animals observed exhibiting them), and leaf-shredding resembles prey-tearing and wiping behaviour, as well as removal of prey items to a perch for processing (Hartdegen et al., 1999; 2000) that these lizards already engage in. The high propensity for monitor lizards to engage in predatory behaviour may mean that this sort of general pattern of movement has the lowest behavioural threshold in this group, and therefore is the most likely to spill over into primary-process play.

Within animal groups, propensity for play appears to be correlated with brain size (Iwaniuk, 2001). Primates display the highest concentration of play behaviours of all mammals (see Burghardt, 2014), and this may be linked to their relatively high energy efficiency in the cost of maintenance and growth (Burgardt, 2014; Pontzer et al., 2014), which provides the excess energy required to facilitate both increased cognitive capacity and primary-process play. Monitor lizards, with their (for squamates) high cognitive capacity and problemsolving abilities (Cooper et al., 2000; Manrod et al., 2008; Gaalema, 2011; Mendyk \& Horn, 2011), dextrous appendages and acute vision, may be regarded in some ways as being to squamates as primates are to mammals. Monitor lizards are relatively energy efficient (e.g. Dryden et al., 1990) and this may contribute to the appearance of primary-process play in this group of reptiles. Moreover, in captivity food is not a scarce resource and so conditions may be even more suitable for the development of primary-process play through SRT than in nature. It is important to note that the captive environment may be less stimulating than the wild one, and this may contribute to the development of behaviours such as those documented here, as animals may seek to create their own diversions in the absence of extrinsic ones.

The mapping of play behaviour in non-mammalian taxa is still only in its infancy. With only scattered reports of play behaviour, it is currently not possible to fully understand its phylogenetic distribution or diversity, and subsequently its evolutionary origins. We recommend that people working with these groups in the field or in captivity report similar observations to add to a growing catalogue of candidate play behaviour in non-mammals.

\section{ACKNOWLEDGEMENTS}

The authors would like to thank keeping teams at both ZSL 
London Zoo and Bristol Zoo for help in maintaining these animals, and to Ben Tapley, Lisa Clifforde, Jim Mackie and Lewis Rowden (ZSL) for their comments on the manuscript.

\section{REFERENCES}

Burghardt, G.M. (1984). On the origins of play. In Play in Animals and Humans, 5-41 pp. Smith, P.K. (Ed.). Oxford: Blackwell.

Burghardt, G.M. (2005). The Genesis of Animal Play: Testing the Limits. Cambridge: MIT Press. 507pp.

Burghardt, G.M. (2014). A brief glimpse at the long evolutionary history of play. Animal Behavior and Cognition 1: 90-98.

Burghardt, G. M, Chiszar, D., Murphy, J. B., Romano Jr., J., Walsh, T. \& Manrod, J. (2002). Behavioural Complexity, Behavioural Development, and Play. In: Komodo Dragons: Biology and conservation, 78-117pp. Murphy, J.B., Ciofi, C., de La Panouse, C. \& Walsh, T. (Eds.). Washington, D.C.: Smithsonian Institution Press.

Burghardt, G.M., Dinets, V. \& Murphy, J.B. (2015). Highly repetitive object play in a cichlid fish (Tropheus duboisi). Ethology 121: 38-44.

Burghardt, G.M., Ward, B. \& Rosscoe, R. (1996). Problem of reptile play: Environmental enrichment and play behavior in a captive Nile soft shelled turtle, Trionyx triunguis. Zoo Biology 15: 223-238.

Cooper, T., A. Liew, G. Andrle, E. Cafritz, H. Dallas, T. Niesen, E. Slater, J. Stockert, T. Vold, M. Young and J. Mendelson III. (2019). Latency in problem solving as evidence for learning in varanid and helodermatid lizards, with comments on foraging techniques. Copeia 107: 78-84.

Dinets, V. (2015). Play behavior in crocodilians. Animal Behavior and Cognition 2: 49-55.

Dryden, G., Green, B., King, D. \& Losos, J. (1990). Water and energy turnover in a small monitor lizard, Varanus acanthurus. Wildlife Research 17: 641-646.

Gaalema, D.E. (2011). Visual discrimination and reversal learning in rough-necked monitor lizards (Varanus rudicollis). Journal of Comparative Psychology 125: 246.

Gaulke, M., Altenbach, A.V., Demegillo, A. \& Struck, U. (2007). On the diet of Varanus mabitang. In: Advances in Monitor Research III, 228-239. Horn, H.G., Böhme, W. \& Krebs, U. (Eds). Bonn: DGHT.

Greene, H.W. (1986). Diet and arboreality in the emerald monitor, Varanus prasinus, with comments on the study of adaptation. Fieldiana Zoologica 31: 1-12.

Gunawardena, S.A. (2016). Forensic significance of monitor lizard scavenging activity on human corpses. Biawak 10: 45-47.

Hartdegen, R. W, Chiszar, D., \& Murphy, J. B. (1999). Observations on the feeding behavior of captive black tree monitors, Varanus beccari. Amphibia-Reptilia 20: 330-332.

Hartdegen, R. W. (2000). Laceration of prey integument by Varanus prasinus (Schlegel, 1839) and Varanus beccarii (Doria, 1874). Hamadryad 25: 196-198.

Held, S.D. \& Špinka, M. (2011). Animal play and animal welfare. Animal behaviour 81: 891-899.

Hill, C. (1946). Playtime at the zoo. Zoo-Life 1: 24-26.
Irwin, S. (1994). Notes on behaviour and diet of Varanus teriae Sprackland, 1991. Memoirs of the Queensland Museum 35: 128.

Irwin, S. (1996). Capture, field observations and husbandry of the rare canopy goanna. Thylacinus 21: 12-19.

Iwaniuk, A.N., Nelson, J.E. \& Pellis, S.M. (2001). Do bigbrained animals play more? Comparative analyses of play and relative brain size in mammals. Journal of Comparative Psychology 115: 29.

Koch, A., Arida, E. (2017). A coconut-eating monitor lizard? On an unusual case of frugivory in the melanistic Sulawesi water monitor (Varanus togianus). Herpetological Bulletin 139: 41.

Kramer, M. \& Burghardt, G.M. (1998). Precocious courtship and play in emydid turtles. Ethology 104: 38-56.

Kuba, M.J., Byrne, R.A., Meisel, D.V. \& Mather, J.A. (2006). When do octopuses play? Effects of repeated testing, object type, age, and food deprivation on object play in Octopus vulgaris. Journal of Comparative Psychology 120: 184-190.

Law, S.J., De Kort, S.R., Bennett, D. \& Van Weerd, M. (2018). Diet and habitat requirements of the Philippine endemic frugivorous monitor lizard Varanus bitatawa. Biawak 12: 12-22.

Lazell, J.D. \& Spitzer, N.C. (1977). Apparent play behavior in an American alligator. Copeia 1977: 188-188.

Losos, J.B. and Greene, H.W. (1988). Ecological and evolutionary implications of diet in monitor lizards. Biological Journal of the Linnean Society 35: 379-407.

Manrod, J.D., Hartdegen, R. \& Burghardt, G.M. (2008). Rapid solving of a problem apparatus by juvenile black-throated monitor lizards (Varanus albigularis albigularis). Animal Cognition 11: 267-273.

Mendyk, R.W. \& Horn, H.G. (2011). Skilled forelimb movements and extractive foraging in the arboreal monitor lizard Varanus beccarii (Squamata: Varanidae). Herpetological Review 42: 343-349

Parry, N.E. (1932). Some notes on water monitors in the Garo Hills, Assam. Journal of the Bombay Natural History Society 35: 903-905.

Pontzer, H., Raichlen, D.A., Gordon, A.D., Schroepfer-Walker, K.K., Hare, M.C., O'Neill, M.F., Muldoon, K.M., Dunsworth, H.M., Wood, B.M., Isler, K., Burkart, J., Irwin, M., Shumaker, R.W., Lonsdorf, E.W. \& Ross, S.R. (2014). Primate energy expenditure and life history. PNAS 111: 1433-1437.

Sprackland, R. G. (1982). Feeding and nutrition of monitor lizards in captivity and in the wild. Kansas Herpetological Society Newsletter 47: 15-18.

Vogel, P. (1979). Zur Biologie des Bindenwarans (Varanus salvator) im westjavanischen Naturschutzgebiet Ujung Kulon. PhD. Thesis, University of Basel, Switzerland, 139 pp.

Ziegler, T., Strauch, M., Pes, T., Konas, J., Jirasek, T., Rütz, N., Oberreuter, J. \& Holst, S. (2009). First captive breeding of the blue tree monitor Varanus macraei Böhme \& Jacobs, 2001 at the Pilzen and Cologne Zoos. Biawak 3: 122-133.

Accepted: 4 August 2019 